\title{
MARTÍ Y LA PSICOLOGÍA
}

\author{
Diego Jorge González Serra \\ Universidad de la Habana, Habana, Cuba
}

RESUMEN: El objetivo del presente trabajo es demostrar que existe un pensamiento psicológico en José Martí. Se señala el criterio martiano de la unidad de observación y reflexión como base de la ciencia, su pensamiento multilateral y sintético, su promoción explícita de la ciencia del espíritu, su concepción sobre la unidad de lo general, lo particular y lo individual en el hombre, sus ideas sobre el pensamiento, la imaginación, la inteligencia, la afectividad, sobre la unidad del conocimiento y el afecto y sobre el espíritu de los pueblos.

PALABRAS CLAVE: José Marti; Psicología.

\section{MARTÍ E A PSICOLOGIA}

RESUMO: O objetivo deste trabalho é demonstrar que existe um pensamento psicológico de José Martí. Destacamse o critério martiano da unidade de observação e reflexão como base da ciência, o seu pensamento multilateral e sintético, sua promoção explícita da ciência do espírito, sua concepção sobre a unidade do geral, o particular e o individual no homem, suas ideias sobre o pensamento, a imaginação, a inteligência, a afetividade, sobre a unidade do conhecimento e do afeto e sobre o espírito dos povos.

PALAVRAS-CHAVE: José Marti; Psicologia.

\section{MARTI'S PSYCHOLOGICAL IDEAS}

ABSTRACT: The aim of the present paper is to bring to light Marti's psychological ideas. The paper discusses Marti's concepts on the science of the spirit. It deals with his beliefs on the unity of observation and thinking as the basis of science; with his multilateral and synthetic thinking; with his ideas regarding the unity of the general, the particular and the individual in man; with his concepts of thinking, imagination and intelligence, moral and motivation; with his beliefs on the unity of cognition and affection, and with his ideas on the spirit of peoples.

KEYWORDS: José Marti, Psychology

José Martí (1853 - 1895), Héroe Nacional de la República de Cuba, fue el organizador e iniciador de la guerra de independencia que finalmente liberó a Cuba de España. Se destacó como político, periodista, poeta, $\mathrm{y}$ como un gran pensador.

El objetivo central del presente artículo es demostrar que existe un pensamiento psicológico en José Martí. Nuestra hipótesis es que Martí expresó criterios, formuló aseveraciones u opiniones sobre temáticas que han sido tradicionalmente objetos de la psicología. En la extensa revisión que hemos realizado de la bibliografía pasiva sobre José Martí no hemos encontrado libros ni artículos donde explícitamente se estudien sus ideas psicológicas.

\section{En el contexto filosófico}

En el contexto de sus notas sobre filosofía Martí nos habla del espíritu y de las vías de su conocimiento e investigación. Ve las fuentes del conocimiento en la unidad de observación y reflexión. Dice: "Razón práctica no quiere decir razón material, sino razón experimental". (Martí, 1975o, p. 362). En el contexto de la práctica no reduce la observación a su aspecto material, sino que incluye también la consideración del espíritu. Sobre su método de pensamiento dice:

Método bueno filosófico es aquel que, al juzgar al hombre lo toma en todas las manifestaciones de su ser; y no deja en la observación por secundario y desdeñable lo que, siendo tal vez por su confusa y difícil esencia primaria no le es dado fácilmente observar. (Martí, 1975o, pp. 364-365).

Este enfoque multilateral y sintético del pensamiento martiano se expresa de manera notable en sus concepciones psicológicas. El Apóstol concibe el espíritu como la unidad de los opuestos. (AQUÍ PONGO PUNTO Y APARTE)

Define el espíritu diciendo: "Lo que no se puede tocar ni ver es invisible e intangible" (Martí, 1975o, p. 
360). Para él: "Naturaleza es todo lo que existe, en toda forma, espíritus y cuerpos" (Martí, 1975o, p. 364). O sea, el espíritu existe al igual que los cuerpos y ambos forman parte de la naturaleza.

En todo el decurso de su obra se pregunta sobre las relaciones entre el espíritu y el cerebro. Se niega a reducir el espíritu a características anatómicas o fisiológicas, pero a la vez reconoce la necesidad de tener en cuenta al cuerpo y al cerebro en unidad con el espíritu.

Para comprender mejor el concepto martiano de espíritu y la relación de éste con la naturaleza y el cerebro deben tenerse en cuenta las siguientes afirmaciones del Apóstol:

Que cada grano de materia traiga en sí un grano de espíritu, quiere decir que lo trae, más no que la materia produjo al espíritu: quiere decir que coexisten, no que un elemento de este ser compuesto creó el otro elemento. !Y ese sí es el magnífico fenómeno repetido en todas las obras de la naturaleza: la coexistencia, la interdependencia, la interrelación de la naturaleza y el espíritu. (Martí, 1975s, p. 317).

Y en 1888 es partidario de "lo que la naturaleza enseña en el desarrollo simultáneo y unido de lo corpóreo e incorpóreo del hombre" (Martí, 1975i, p. 479).

\section{La "Ciencia del Espíritu"}

En los momentos en que surgía en el mundo la psicología como disciplina independiente de la filosofía, José Martí planteó y fundamentó la necesidad e importancia de la "ciencia del espíritu" basada en hechos.

En su Cuaderno de Notas \# 4 escrito probablemente entre los años 1878 y 1880 (o sea, cuando W. Wundt fundaba en Leipzig su laboratorio de psicología experimental que marca el inicio de esta ciencia particular) el joven José Martí dice: "La vida humana es una ciencia" (Martí, 1975q, p. 137).

En 1882 expresa: "El alma ha de estudiarse como el cuerpo" (Martí, 1975s, p. 212). En 1883 dice: "La ciencia del espíritu, menos perfeccionada que las demás por estar formada de leyes más ocultas y hechos menos visibles, ha de construirse sobre el descubrimiento, clasificación y codificación de los hechos espirituales" (Martí, 1975f, p. 347). Esta es la primera vez en sus escritos que Martí habla de "Ciencia del Espíritu", de "leyes" de esta ciencia y de "hechos espirituales".

Es en un breve artículo para La América de Nueva York, en mayo de 1884, donde el Maestro nos ofrece su único y más importante trabajo dedicado por entero a su concepción y a su promoción de la psicología científica. Allí dice: "la filosofía materialista, al extremar sus sistemas, viene a establecer la indispensable necesidad de estudiar las leyes del espíritu.” (Martí, 1975m, p. 395).
Exagerando un poco podríamos decir que este es el manifiesto psicológico de José Martí donde plantea la indispensable necesidad de desarrollar la ciencia del espíritu, de descubrir sus leyes, leyes generales que no se contradicen con la originalidad fructífera e individualidad de la persona humana, porque el hombre no es una entidad definitivamente aislada sino que pertenece a tipos, y responde a regularidades. Y nos habla de los egoístas y los altruistas y de esos momentos luminosos en que "hombres acumulados" ponen cada vez más alto la bandera humana, porque ésta es también una "ley del espíritu". Y repite: "La vida espiritual es una ciencia, como la vida física" (Martí, 1975m, p. 396). Y a continuación aborda el problema de la herencia de los atributos psicológicos en el hombre, asumiendo un enfoque multilateral, sintético.

Exageramos porque no se trata de un científico, sino de un periodista y un político, pero decimos "manifiesto psicológico" porque aquí Martí se manifiesta partidario de la psicología científica, basada en hechos, y descubridora de leyes, a la vez que le aporta una metodología teórica, una manera de pensar multilateral y sintética.

Y en los hechos del espíritu Martí incluye las vivencias, pero también los datos de la conducta. Dice: "Vive con un hombre; sólo así sabrás quien es." (Martí, 1975q, p. 76). Pues el Apóstol no separó el espíritu de la actividad del hombre, sino que apreció su unidad, su identidad y continuidad.

\section{EI concepto de hombre}

El tema del hombre se encuentra en todo el decurso de la obra del Maestro. Este es un concepto clave pues su esclarecimiento le resultó imprescindible para luchar por el mejoramiento humano, superioridad de unas razas y pueblos sobre otros y plantear la necesidad de forjar el "hombre real" latinoamericano.

El Apóstol apreció la unidad de lo general, lo particular y lo individual en el hombre. Destacó lo general cuando habló de la identidad del hombre. Dice: "Razas, lenguas, historia, religiones, todo eso son vestiduras de quitaipón, debajo de las cuales surge, envolviéndolas y dominándolas, la esencial e invariable naturaleza humana..." (Martí, 1975h, p. 475).

Y si se quiere conocer en qué consiste esta esencial identidad, creemos interpretar fielmente al Apóstol cuando destacamos:

\section{1 - "El hombre es exógeno y endógeno" (Martí, 1975r, p. 225).}

En su biografía de H.W. Beecher dice: "Nada es un hombre en sí, y lo que es, lo pone en él su pueblo." 
"Los hombres son productos, expresiones, reflejos." (Martí, 1975k, p. 34).

Pero también nos dice: "Fuerza es que cada hombre ... se labre a sí propio." (Martí, 1975g, p. 272). "El hombre debe realizar su naturaleza" (Martí, 1975b, p. 479). Así señaló tanto la determinación externa (o exógena) del hombre, como su carácter activo y creador de sí mismo, su autodeterminación (endógena).

\section{2 - El hombre es "una fiera educada".}

Define: "El hombre, en verdad, no es más, cuando más es, que una fiera educada. Eternamente igual a sí propio... si en lo esencial suyo no cambia, cambia y mejora con el conocimiento de los objetos de la vida y de sus relaciones." (Martí, 1983, p. 74). De esta manera concibió la unidad en el hombre de lo natural (la fiera) y lo espiritual o superior (su educación). En consecuencia se opone a los criterios puramente biologistas e innatistas e integra la determinación innata con la adquirida. Dice que "cada hombre es en sí el resumen de los tiempos" (Martí, 19751, p. 347). Pues "en el espíritu del hombre están... todas las edades de la Naturaleza" (1975f, p. 333), "cada hombre lleva en sí todo el mundo animal" (1975h, p. 79) y "la vida individual es un resumen breve de la vida histórica... la vida de un hombre copia la vida de una nacionalidad" (1975o, pp. 441-442). O sea, el Apóstol concibió al hombre como la expresión y el resultado del desarrollo natural e histórico social.

\section{3 - La interpenetración del espiritu del hombre y el del pueblo en que viene a la vida.}

Martí señaló la unidad de individuo y sociedad. El hombre es a la vez una expresión y un determinante activo de su pueblo.

Hasta aquí hemos visto en qué consiste para el Maestro la identidad del hombre, o sea, su naturaleza general, esencial, invariable, pero también señaló lo particular en el ser humano, debido a diferencias hereditarias, raciales, culturales, de personalidad y de circunstancia. En "Nuestra América", teniendo en cuenta las particularidades raciales, étnicas y condiciones geográficas de los hombres de América Latina, planteó el concepto de "hombre natural", o sea, el hombre que constituye un reflejo de dichas particularidades y condiciones. Es necesario crear los métodos, las instituciones, el gobierno y la cultura que se correspondan con estas características. Sólo así surgirá el "hombre real" de Nuestra América. Si las instituciones, si la cultura, son exóticas, tomadas a otras naciones quizás más desarrolladas, no responden al "hombre natural" y éste las rechaza. Así su concepto de hombre orientó al Apóstol en su lucha en favor de nuestra América.
Y, además de señalar lo particular, destacó que "la individualidad es el distintivo del hombre" (Martí, 1975m, p. 398).

\section{Pensamiento, imaginación e inteligencia}

En los años 75 y 76, en México, aparece su primera preocupación por la inteligencia latinoamericana. Durante su larga estancia en Estados Unidos dejó escritas muy diversas observaciones sobre el intelecto humano que denotan su interés permanente por esta temática hasta el último momento de su vida.

Durante sus años de periodista en México y otros países de Latino América vio en las características intelectuales de los pueblos de nuestra América una causa de su estancamiento y atraso.

Expresa en México en julio de 1875:

La inteligencia tiene dos fases distintas: la de creación y la de aplicación, cuando aquélla no se une a ésta, hace desventurados y mártires, enfermos incurables del dolor perpetuo de la vida: la de aplicación, con ser menos noble, es más adecuada y necesaria a la existencia: una y otra mezcladas son el germen escondido del bienestar de un país.

Mas dadas son a crear que a aplicarse las inteligencias de tierra americana; pero como no tiene medios de realización, su potencia creadora busca en vano lo práctico, vaga por lo único que es suyo, vuela errante por lo improductivo y lo ilímite y hace de la vida oficio de poeta, el que tiene el deber formal de hacerla oficio de hombre. (Martí, 1975d, p. 270).

En octubre del mismo año plantea una tesis que repite en varias ocasiones: "La inteligencia y la imaginación tienen cualidades de esencia distinta; el estudio reflexivo, que dañaría a la imaginación, a la inteligencia es necesario y aprovecha." (Martí, 1975d, p. 351).

Donde nos parece que ofrece la solución al problema psicológico y a la vez social que plantea es en una nota sin fecha para la preparación de un artículo donde dice:

No hay que rebajar las condiciones que se tienen: sino equilibrarlas por el realce o adquisición de las que no se tienen. Para dar a los pueblos de la América del Sur lo que les falta, no hay que rebanarles la hermosa imaginación, sino levantarla, dotarlos de razón en igual grado. Lo contrario sería mejorar perdiendo... Preservad la imaginación, hermana del corazón... Los pueblos que perduran en la historia son los pueblos imaginativos. Y cread al pueblo sumo, rico sin rival en naturaleza, rico sin rival en imaginación, rico sin igual en razón (Martí, 1975s, pp. 43-44).

Interpretando al Apóstol entendemos que los pueblos de Latino América son más dados a crear que 
a aplicar su inteligencia; en ellos, predomina la imaginación no subordinada a la razón y esto los conduce a no resolver los problemas prácticos y desviarse, a hacer vida de poeta y a una improductiva y conflictiva vida político social. La solución está en desarrollar la razón y la aplicación de la inteligencia a la solución de los problemas prácticos. No está en disminuir la imaginación que también tiene un rol fundamental en la vida de los pueblos.

Véase cómo para Martí el esclarecimiento de una problemática psicológica constituye a la vez la búsqueda de una solución a los problemas de nuestra América. Debe saberse que el Apóstol habló de los procesos intelectuales conscientes, pero también se interesó por los involuntarios, automáticos e intuitivos.

\section{Moral y ciencia del espíritu}

¿Quién duda que la moral es el centro de gravedad del Ideario Martiano? En su empeño por forjar el patriotismo, construir nuestra república, salvar a Latino América y mejorar al hombre, vio en la formación moral el arma fundamental.

Sin embargo, la educación moral y política requiere imprescindiblemente el esclarecimiento de conceptos y leyes de la ciencia del espíritu, aquellos referentes a la motivación, las necesidades y su dinámica funcional. Por ello pensamos que las ideas psicológicas del Maestro tuvieron su mayor desarrollo en estas temáticas morales y aquí se presentan dispersas e inconexas, como prédica moral, como ideas políticas, como comentarios periodísticos y críticas de arte. Por ello pueden pasar inadvertidas para quien no tenga "olfato" psicológico.

Martí puso en el centro de la educación moral el conflicto entre altruismo y egoísmo (la virtud, la generosidad, el amor a la patria y a la humanidad en conflicto con la ambición personal, el afán de lucro, la irresponsabilidad y el abandono de los deberes). Y a esto añadió otro importante y también decisivo requerimiento moral del hombre: la independencia, la libertad, la creatividad.

En su "manifiesto psicológico" planteó una tipología:

la división entre egoístas y altruistas, entre aquellos que viven exclusivamente para su propio beneficio...; y aquellos a quienes más que el propio bien, o tanto por lo menos, preocupa el bien de los demás. El avaro es el tipo esencial del egoísta; el héroe es el tipo esencial del altruista. (Martí, 1975m, p. 396).

Ya anteriormente había señalado una jerarquía motivacional: "el hombre por esencia individualista" (Martí, 1975d, p. 277). "En las almas, hay dos huéspedes: el deber, pigmeillo; y el apetito, voraz gigante.
Uno es el objeto de los hombres: improvisar riquezas." (Martí, 19751, p. 491).

Definió el carácter como "el denuedo para obrar conforme a la virtud, que tiene como enemigos los consejos del mundo y los afectos más poderosos en el alma." (Martí, 1975c, p. 143). E igualmente expresa: “el desinterés, raíz del carácter" (Martí, 1975j, p. 27).

En 1880 escribe a Miguel Biondi sobre un libro que ya se preparaba a redactar, pero que debió posponer: "Examinaré en él esa vida falsa que las convenciones humanas ponen en frente de nuestra verdadera naturaleza, torciéndola y afeándola" (Martí, 1975p, p. 284).

El Apóstol dice:

Así es la tierra ahora una vasta morada de enmascarados. Se viene a la vida como cera, y el azar nos vacía en moldes prehechos. Las convenciones creadas deforman la existencia verdadera, y la verdadera vida viene a ser como corriente silenciosa que se desliza invisible bajo la vida aparente, no sentida a veces por el mismo en quien hace su obra cauta...Asegurar el albedrío humano; dejar a los espíritus su seductora forma propia; no deslucir con la imposición de ajenos prejuicios las naturalezas vírgenes; ponerlas en aptitud de tomar, por sí lo útil, sin ofuscarlas, ni impelerlas por una vía marcada. !He ahí el único modo de poblar la tierra de la generación vigorosa y creadora que le falta!. (Martí, 1975e, p. 230).

Expresa en otros lugares de su obra: "Fuerza es que cada hombre, con sus manos tenaces se labre a sí propio" (Martí, 1975g, p. 272). "El hombre debe realizar su naturaleza." (Martí, 1975b, p. 474). La psicología contemporánea ha llamado "auto realización” a esto último.

Así vemos como las exigencias morales del Apóstol, el altruismo y la autodeterminación, lo llevaron a esclarecer conceptos que hoy en día pertenecen a la psicología.

Debe saberse que el Maestro nos habló de la motivación consciente, pero también de la inconsciente, la que apreció sobre todo en lo que llamó "compensación" de necesidades.

\section{La unidad del conocimiento y el afecto}

Por propia convicción filosófica y por ser brújula guiadora de su práctica, el Maestro enfatizó la unidad del conocimiento y el afecto. Veamos sus expresiones: "se necesita abrir una campaña de ternura y de ciencia" (Martí, 1975f, p. 291). "No son inútiles la verdad y la ternura" (Martí, 1975p, p. 475). "Pero seré mientras viva, en el Cayo como en el monte, fortaleza de verdad y amor. Con la realidad y por el cariño." (Martí, 1975a, p. 268).

En sus notas mas tempranas redactadas en su primera deportación, cuando estudiaba en España, 
expresa: "Al alma pertenecen las facultades volitivas, intelectuales y sentimentales." (Martí, 1975q, p. 48).

En todo el decurso de su obra el Maestro destaca la unidad, la identidad, la penetración recíproca del intelecto y el afecto. Para él la voluntad y la motivación actúan dentro del pensamiento, el genio es una fuerza que mueve, crea o destruye; y a su vez el conocimiento actúa dentro de la voluntad, dentro de la motivación, querer es saber, sin saber no se puede querer. Igualmente piensa que "la inteligencia da bondad, justicia y hermosura" (Martí, 1975c, p. 108); y también afirma lo inverso, que "la virtud es un hada benéfica...da a la mente las fuerzas del genio" (Martí, 1975g, p. 134). Lo dice claramente: "no hay buena educación sin instrucción. Las cualidades morales suben de precio cuando están realzadas por las cualidades inteligentes." (Martí, 1975o, p. 375), "el cultivo de la inteligencia ennoblece." (Martí, 1975d, p. 267).

Pero también afirma lo inverso: "el don de amor, lo que hace fecundo al genio.” (Martí, 1975f, p. 410); " "por ser a las claras un hombre bueno, que es la primera condición para ser inteligente de veras" (Martí, 1975e, p. 371); "la ley del talento...es el desinterés." (Martí, 1975j, p. 473).

En la conclusión de su cuento "Meñique" el Maestro nos legó a los psicólogos una profunda idea que obliga a pensar. Dice: "el que es estúpido no es bueno; y el que es bueno no es estúpido. Tener talento es tener buen corazón; el que tiene corazón, ése es el que tiene talento." (Martí, 1975n, p. 324).

\section{El espíritu de los pueblos}

¿Se interesó el Apóstol por la psicología social?

En su obra podemos leer observaciones, criterios y análisis psicológicos sobre la unidad de individuo y sociedad. Sobre el espíritu de pueblos, razas y etnias, y sobre la identidad nacional. El Maestro señaló: "esa interpenetración misteriosa del espíritu del hombre y el del pueblo en que viene a la vida" (Martí, 1975h, p. 62).

Para Martí la correcta formación del individuo conduce al esplendor del pueblo; pero también lo inverso es cierto: los individuos son formados por el pueblo, son reflejos del pueblo. El hombre es una manifestación de su pueblo, y este último vive y existe a través de los hombres que lo componen.

Diversos escritos del Maestro abordan las causas subjetivas de las dificultades y limitaciones de los pueblos de nuestra América y del pueblo norteamericano, las características psicológicas de la raza negra, de los indios de América, y el análisis psicológico de la situación de los cubanos en la emigración.

Para un patriota que lucha por la independencia de su tierra el concepto de identidad nacional resulta decisivo. Y este es el caso de José Martí.
Especial atención prestó a la diferencia entre, de un lado, los pueblos de nuestra América, y, del otro, los pueblos de la América que no es nuestra. Los pueblos latinoamericanos - incluyendo el cubano - vivimos devorados por la persecución infatigable de un ideal de amor o de gloria, sólo amamos lo que nos pone en riesgo y nos agita.

El pueblo norteamericano es turbado sólo por el ansia de posesión de una fortuna, vive vacío de espíritu, no hace cosa sin objeto, quiere vaciar donde lo vean lo que gana donde no lo vean, se vende y cree que todo se compra, la vida no es más que la conquista de la fortuna y se les va en ganar y ostentar. los hombres compran a las mujeres con joyas y vestidos, como juguetes de lujo.

Fruto del análisis de la psicología de ambos pueblos el Apóstol señala lo que considera la sociedad ideal:

Hay por suerte un equilibrio perpetuo tanto en la naturaleza de los pueblos como en la de los hombres. La fuerza de la pasión esta contrapesada por la fuerza del interés. Un apetito insaciable de gloria lleva a los hombres al sacrificio y a la muerte, pero un instinto innato los lleva al ahorro y a la vida. La nación que descuida una de esas fuerzas, muere. Hay que guiarlas juntas, cual la pareja de caballos de un carruaje. Y ésa es la razón de las desgracias de los países sudamericanos: la fuerza de la pasión ha sido allí hasta hoy más grande que la fuerza del interés. Se desprecia el dinero: se adora a la idea. Ser rico no es allí sino algo secundario. Ser conocido, ser glorioso, es grande: ése es el objetivo de sus esfuerzos. (Martí, 1975o, pp. 154-155).

Basado en este mismo criterio se opone al espíritu enmonedado y puramente práctico del pueblo norteamericano.

Véase cómo en el pensamiento del Apóstol los conceptos teóricos acerca de la identidad espiritual de los pueblos sirven de base a empeños independentistas, morales y de progreso social.

\section{Conclusión: Martí y el futuro de la Psicología}

Aquí llegamos al final de este artículo. Nuestro objetivo ha quedado cumplido y nuestra hipótesis ha sido demostrada: José Martí tiene un pensamiento psicológico.

¿Qué ha legado el Apóstol a la psicología del futuro, del siglo XXI? Expresemos nuestro punto de vista.

1ero) La fuente del conocimiento: la unidad de observación y reflexión: la práctica y los hechos como base de la ciencia que incluye tanto las vivencias como la observación externa de la conducta.

2do) El método multilateral, que une el análisis con la síntesis, pues "lo verdadero es lo sintético" 
(Martí, 1975d, p. 233). Sus concepciones psicológicas son multilaterales e indican una gran tarea para la psicología del siglo XXI: trabajar por la síntesis de todas las corrientes teóricas que en el siglo XX han sido unilaterales y sólo analíticas, acabar con el sectarismo y el dogmatismo, superar a todas las escuelas para fundar una sola: la Ciencia Psicológica.

3ero) La unidad de lo científico y lo ideológico (la moral, el arte, la política). El Apóstol fue un fervoroso partidario de la verdad científica basada en hechos, pero puso todos sus conocimientos psicológicos al servicio de la moral, los vinculó al arte y los empeñó en la tarea de luchar por la libertad de Cuba, Latino América y todos los pueblos del mundo.

Las ideas psicológicas de José Martí constituyen una parte fundamental de su teoría de la liberación de los pueblos (centrada en Cuba y Latino América) y el fundamento de sus concepciones sobre la formación de un hombre espiritualmente superior que garantice la libertad y la independencia.

$\mathrm{Su}$ ejemplo como pensador y hombre de acción nos enseña a ser psicólogos comprometidos con la moral y con la lucha por la libertad, la justicia social y por un hombre nuevo y superior.

El Ideario Martiano plantea tres tareas fundamentales a la psicología del siglo XXI: luchar por un hombre altruista (entregado a la patria y a la humanidad), creador y libre (que no sea víctima de la convención ni del formalismo, que pueda realizar su naturaleza). He aquí el único modo de poblar la tierra de una generación vigorosa y creadora que le falta.

Es increíble la actualidad del pensamiento del Apóstol. La luz de su genio ilumina el presente y el futuro de la humanidad.

Con este artículo (resumen del libro inicialmente indicado), en representación de la psicología cubana, rendimos tributo de infinito reconocimiento a nuestro gran pensador, a uno de los hombres que más hizo por fundar la libertad que tenemos y que, renaciendo de su obra eterna, nos indica el camino.

\section{Referencias}

González, D. J. (1999). Martí y la Ciencia del Espíritu. La Habana: Editorial Si - Mar S.A.

Martí, J. (1975a). Obras Completas (Vol. 2). La Habana: Editorial de Ciencias Sociales.
Martí, J. (1975b). Obras Completas (Vol. 4). La Habana: Editorial de Ciencias Sociales.

Martí, J. (1975c). Obras Completas (Vol. 5). La Habana: Editorial de Ciencias Sociales.

Martí, J. (1975d). Obras Completas (Vol. 6). La Habana: Editorial de Ciencias Sociales.

Martí, J. (1975e). Obras Completas (Vol. 7). La Habana: Editorial de Ciencias Sociales.

Martí, J. (1975f). Obras Completas (Vol. 8). La Habana: Editorial de Ciencias Sociales.

Martí, J. (1975g). Obras Completas (Vol. 9). La Habana: Editorial de Ciencias Sociales.

Martí, J. (1975h). Obras Completas (Vol. 10). La Habana: Editorial de Ciencias Sociales.

Martí, J. (1975i). Obras Completas (Vol. 11). La Habana: Editorial de Ciencias Sociales.

Martí, J. (1975j). Obras Completas (Vol. 12). La Habana: Editorial de Ciencias Sociales.

Martí, J. (1975k). Obras Completas (Vol. 13). La Habana: Editorial de Ciencias Sociales.

Martí, J. (19751). Obras Completas (Vol. 14). La Habana: Editorial de Ciencias Sociales.

Martí, J. (1975m). Obras Completas (Vol. 15). La Habana: Editorial de Ciencias Sociales.

Martí, J. (1975n). Obras Completas (Vol. 18). La Habana: Editorial de Ciencias Sociales.

Martí, J. (1975o). Obras Completas (Vol. 19). La Habana: Editorial de Ciencias Sociales.

Martí, J. (1975p). Obras Completas (Vol. 20). La Habana: Editorial de Ciencias Sociales.

Martí, J. (1975q). Obras Completas (Vol. 21). La Habana: Editorial de Ciencias Sociales.

Martí, J. (1975r). Obras Completas (Vol. 22). La Habana: Editorial de Ciencias Sociales.

Martí, J. (1975s). Obras Completas (Vol. 23). La Habana: Editorial de Ciencias Sociales.

Martí, J. (1983). Otras Crónicas de Nueva York. La Habana: Editorial de Ciencias Sociales.

Diego Jorge González Serra es Profesor Titular Adjunto de la Universidad de la Habana, Cuba. Dirección: Policlínico

Plaza, Ermita y San Pedro. Plaza de La Revolución. Ciudad de La Habana. República de Cuba. Carrera de Psicologia. Universidad de Ciências Médicas. Email: diegonza@infomed.sld.cu

\section{Martí y la Psicología \\ Diego Jorge González Serra}

Recebido em: 23/10/2008

Aceite em: 14/10/2009 